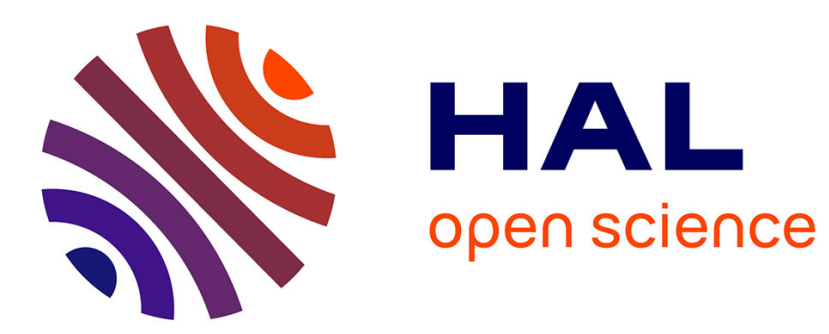

\title{
Mathematics teacher education advanced methods: an example in dynamic geometry
}

\author{
Ghislaine Gueudet, Luc Trouche
}

\section{To cite this version:}

Ghislaine Gueudet, Luc Trouche. Mathematics teacher education advanced methods: an example in dynamic geometry. ZDM Mathematics Education, 2011, 43 (3), pp.399-411. 10.1007/s11858-0110313-x . hal-00605493

\section{HAL Id: hal-00605493 \\ https://hal.science/hal-00605493}

Submitted on 11 Jul 2013

HAL is a multi-disciplinary open access archive for the deposit and dissemination of scientific research documents, whether they are published or not. The documents may come from teaching and research institutions in France or abroad, or from public or private research centers.
L'archive ouverte pluridisciplinaire HAL, est destinée au dépôt et à la diffusion de documents scientifiques de niveau recherche, publiés ou non, émanant des établissements d'enseignement et de recherche français ou étrangers, des laboratoires publics ou privés. 
Gueudet, G., \& Trouche, L. (2011). Mathematics teacher education advanced methods: an example in dynamic geometry. ZDM, the international journal on mathematics education, 43(3), 399-411.

Mathematics teacher education advanced methods: an example in dynamic geometry

Ghislaine Gueudet

Affiliation : CREAD, IUFM Bretagne UBO

e-mail Ghislaine.Gueudet.1@univ-rennes1.fr

Address

153 rue Saint-Malo

35043 RENNES CEDEX

FRANCE

tel $0033(0) 299546689$

fax $0033(0) 299546400$

Luc Trouche

Affiliation : EducTICE INRP

e-mail Luc.Trouche@inrp.fr

Address

19 allée de Fontenay

BP 17424

69347 LYON

FRANCE

\section{Abstract}

We present a research work about an innovative national teacher training program in France: the Pairform@nce program, designed to sustain ICT integration. The Pairform@nce trainings are grounded in a principle of collective lesson design by teams of trainees; they associate face-to-face and distant training. We study here a training for secondary school teachers, whose objective is to foster the development of an inquiry-based approach in the teaching of mathematics, using investigative potentialities of dynamic geometry environments (DGE).

We adopt the theoretical background of the documentational approach to didactics for studying how a training organizing the design of lessons by teachers teams can contribute to teacher professional development, directed in particular towards more inquiry in the classroom supported by DGE. This approach conceptualizes the interactions between teachers and resources as geneses: complex, long-term processes, associating evolutions and stability. In the frame of this approach, for studying these geneses, we develop a specific methodology: we organize a follow-up of teachers during several weeks; during this period, the teachers fill a logbook describing their activity; they answer to questionnaires and interviews; we also collect as completely as possible the material resources involved in their work.

We followed in particular the work of a team of trainees; drawing on the data collected, we analyse their professional development, related with the training. We discuss on a more general level, the consequences of a training based on collective documentation work for the integration of technology by mathematics teachers.

\section{Keywords}

Community of practice; Documentational approach; Dynamic geometry environment (DGE); Inquiry-based learning and teaching, Mathematics teacher education; Training path. 
Gueudet, G., \& Trouche, L. (2011). Mathematics teacher education advanced methods: an example in dynamic geometry. ZDM, the international journal on mathematics education, 43(3), 399-411.

\section{Mathematics teacher education advanced methods: an example in dynamic geometry}

\section{Introduction}

Dynamic geometry environments (DGE) have been developed in the mid of the 1980s, in the thread of the powerful idea of "direct manipulation" (Laborde \& Laborde 2008). Its interest for the learning of geometry appeared right away, as they offered new possibilities for visualization and for checking properties by dragging geometrical objects. This interest has been recognized by many educational systems, which have integrated DGE into their curricula (Kortenkamp et al. 2009). Nevertheless, 25 years afterwards - a quarter of a century - the use of DGE in the mathematics classroom is not so spread; this use appears quite complex to a number of teachers, and the "ordinary" teachers' training devices seem helpless to change this situation.

We want here to address this issue in putting forwards an example of mathematics teacher education advanced method, aiming to foster the use of technology - in this case DGE in mathematics - into classrooms.

In the first section, we present our theoretical perspective, situating it in the dynamic of the field of research: "technology in mathematics teacher education". In the second section, we describe Pairform@nce, an innovative teachers training program, focusing on the case of a DGE training path. In the third section, we analyse the effects of this training path on teachers' knowledge and practices. Finally, we draw, in the conclusion, some perspectives and ask some new questions, about both the training program at stake, and the theoretical framework supporting our research.

\section{Teacher resources and teacher education}

The reflection on technology ${ }^{1}$ in mathematics teacher education is active since 20 years; we enlighten, in this section, its dynamic, and propose our theoretical approach as a mean for understanding deep evolutions and analysing new phenomena in this field.

\subsection{Technology and mathematics teacher education}

We are today far from the naïve idea that "technology makes mathematics teaching easier". A number of studies have put in evidence the didactical cost and the complexity of integrating technology in mathematics teaching. For example, Hennessy et al. (2005, p. 162) note that « Innovation and adaptation are costly in terms of the time needed to develop and establish new practices. In addition to the new interpersonal and pedagogic skills which teachers require to use ICT in their classrooms, other contextual factors which can act as barriers to using ICT include lack of confidence, experience, motivation, and training; access to resources and timetabled use of dedicated ICT class-rooms; unreliability of equipment; classroom practices which clash with the culture of student exploration, collaboration, debate, and interactivity within which much technologybased activity is said to be situated $"$.

In the case of a DGE, Laborde (2001) pointed out that, when it was used, « the software was mainly used as an amplifier for visualizing properties, but not really the source of the task given to the students, nor as a tool for solving the task ». Going further would lead to exploit the "powerful idea of direct manipulation" (§ 1): integrating DGE for conjecturing and supporting a search for evidence would require, for the teacher, to rethink the activity format of her lesson, i.e. " the generic templates for action and interaction which frame the contributions of teacher and students to particular types of lesson » (Ruthven 2007), which is not so easy.

The role of the teacher for ICT integration has appeared, at an international level, as a key question, whose solutions are not obvious: "There was a tendency to focus on teachers' development and an implicit assumption that the transfer of innovative situations of use, possibly supported by outcomes of research, would provide the teacher with sufficient material for an easy integration. Aware of the complexity of teaching and learning situations with ICT, researchers are now more cautious » (Lagrange et al. 2003, p. 259).

Situations of use mean new mathematical activities taking advantage of the software (Laborde 1998). Software, mathematical ideas for taking profit of them and didactical ideas for using them, constitute what we will name "resources" for teachers, today widely available via Internet (Figure 1: 93,300 results given by google.fr when searching something about "dynamic geometry mathematics teaching"). There is obviously a gap between having access to such resources and appropriating them for usage in the classroom. The

\footnotetext{
${ }^{1}$ We use in this article the word "technology" to point out both hardware (computers, interactive white board, calculators) and software (CAS - computer algebra system -, DGE, spreadsheet...) likely to be integrated in mathematics teaching. In the same sense, we use also the acronym ICT (Information and Communication Technology).
} 
Gueudet, G., \& Trouche, L. (2011). Mathematics teacher education advanced methods: an example in dynamic geometry. ZDM, the international journal on mathematics education, 43(3), 399-411.

European project Intergeo (Kortenkamp et al. 2009, Trgalova et al. 2009) is tackling theses issues of designing, sharing and appropriating resources devoted to the use of DGE in the classroom. This wide conceptualisation of resources leads to consider them as a theme for teacher education (Adler 2000).

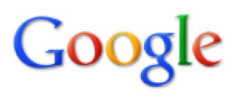

dynamic geometry mathematics teaching

About 93,300 results $(0.35$ seconds)

Everything
Books
All results
Timeline
More search tools

Scholarly articles for dynamic geometry mathematics teaching

A. ...' interpretations when using Dynamic Geometry.... - Jones - Cited by 85 Foundations of dynamic geometry - Kortenkamp - Cited by 107
$\ldots$ in promoting the need to prove in dynamic geometry ... - Hadas - Cited by 60 GeoGebra

GeoGebra. Free mathematics software for learning and teaching. Download · screenshottangents.png. Interactive graphics, algebra and spreadsheet ...

- More search tools www.geogebra.org/ - Cached - Simila

Home - The Geometer's Sketchpad Resource Center

Key Curriculum Press has added Teaching Elementary Math with The ... Dynamic Geometry@ mathematics visualization software, The Geometer's Sketchpad.... unw.dynamicgeometry.com/ - Cached - Similar

Figure 1. Abundance of DGE "resources" available on Internet

Teacher education, supporting teachers' development, appears indeed as a key issue (Artigue 1998) for the integration of computer technologies. About pre-service teacher education on DGE, Tapan (2006) points out the necessary articulation between knowledge on mathematics and on the software, didactical knowledge on mathematics and on the software, needing to carefully organize a work on resources.

About in-service teacher education on ICT, Trouche \& Guin (2005) underlined that usual training strategies in France are essentially based on the transmission of « expert resources ». Mostly organized in a short period (about 3 days), isolated from school practice, they do not allow a continuous support to be provided during the necessary adaptation of resources to each teacher's usage context. To overcome this inadequacy, innovative programs had been developed, from the 1990s, in the US (Allen et al. 1996), lying on teachers' networks, designing, with the help of experts, situations of use for DGE; this perspective of "teachers empowering teachers" appeared powerful, for both integrating DGE and promoting new inquiry-based teaching practices. Trouche \& Guin (ibidem) have taken up this idea, conceptualising collaborative work on resources as a way for teacher education on technology in developing an innovative teacher training program named SFoDEM ${ }^{2}$. More generally, a recent survey (Krainer \& Wood 2008) enlightened the importance of teams, networks and communities for teacher education. Joubert et al. (2009) drew the same lesson, from analyzing several models for teachers continuing professional development, and added to this picture the importance, for a teacher, to experiment in her own class, and to have time away from school for thinking and discussing.

Conceptualising resources as a theme for teacher education, conceptualising collaborative work on resources as a way for teacher education, led us to rethink our theoretical background on teachers' resources, practices and knowledge.

\subsection{From the instrumental to the documentational approach}

The awareness of the complexity of ICT integration in mathematic teaching went, in the 1990s, with the emergence of a new theoretical perspective, the instrumental approach, situating the artefacts as active partners of the learning processes. The understanding of the crucial role of mediation for human development, of course, does not constitute in itself a novelty: Vygotski (1978) already enlightened it. Nevertheless Verillon and Rabardel (1995) developed a seminal approach by distinguishing artefacts, as products of passed human activity, available for further activity ${ }^{3}$, and instruments, as individual constructs, mixed entities made of artefacts and schemes. A scheme is defined by Vergnaud (1998) as an invariant organization of finalised activity, encapsulating knowledge, structured by operational invariants, both result and spring of activity. The development of a document is described as an instrumental genesis. Verillon and Rabardel proposed to distinguish, within this genesis, two processes, instrumentation (the artefact shaping user's activity) and instrumentalisation (the user shaping the artefact), the interaction between these two processes fostering the instrumental geneses.

\footnotetext{
${ }^{2}$ SFoDEM: Suivi de Formation à Distance pour les Enseignants de Mathématiques (meaning "Distance Support for Mathematics Teachers Training").

${ }^{3}$ In this sense, both ICT and old technology (rule and compass, paper and pencil...) constitute artefacts for mathematical activity.
} 
Gueudet, G., \& Trouche, L. (2011). Mathematics teacher education advanced methods: an example in dynamic geometry. ZDM, the international journal on mathematics education, 43(3), 399-411.

This new perspective on instruments has been integrated in the field of mathematics education (Guin \& Trouche 1999), giving birth to the instrumental approach, which, articulated with other theoretical approaches in the field (Artigue 2002), gave new mean for understanding learning processes. For example, in DGE environment, Restrepo (2007) identified various schemes of dragging geometrical objects, some operational invariants involved (for example: « if a conjecture is verified when dragging a figure, therefore it is always true $")$ and analysed their consequences in terms of students' knowledge. The dynamic of this approach leads to reconsider the teacher's responsibility for monitoring students' instrumental geneses: the notion of instrumental orchestrations (Guin \& Trouche 2002, Trouche \& Drijvers 2010), defined as a didactical management, by the teacher, of the artefacts available in a given environment, for tackling a given mathematical activity, thus appeared as a necessity for analyzing teacher' work with technology, both out-ofclass (preparing her teaching) and in class (adjusting it 'on the spot').

This new sensibility to teacher's work raised new questions: what does a teacher work with? With who? When? The digitalization of information and communication in society has strong consequences for teaching: vanishing of the frontiers between hardware, software and situations of use ${ }^{4}$, abundance of 'resources' ( 1.1). The notion of resource thus appears more relevant than 'technology' or 'artefacts' to describe 'what does a teacher deal with?'. This conducts to a more holistic view on teacher's work, considering it both in and out-of-class, wrestling with resources for performing her teaching. We have therefore proposed (Gueudet \& Trouche 2009a) to substitute to the dialectic artefact/instrument a new dialectic between resources and document ${ }^{5}$. We name documentational approach this new perspective on teachers' work: teacher's work consists (Figure 2) in developing documents, along documentational geneses, from set of resources, in a given institution, for a given class of situations.

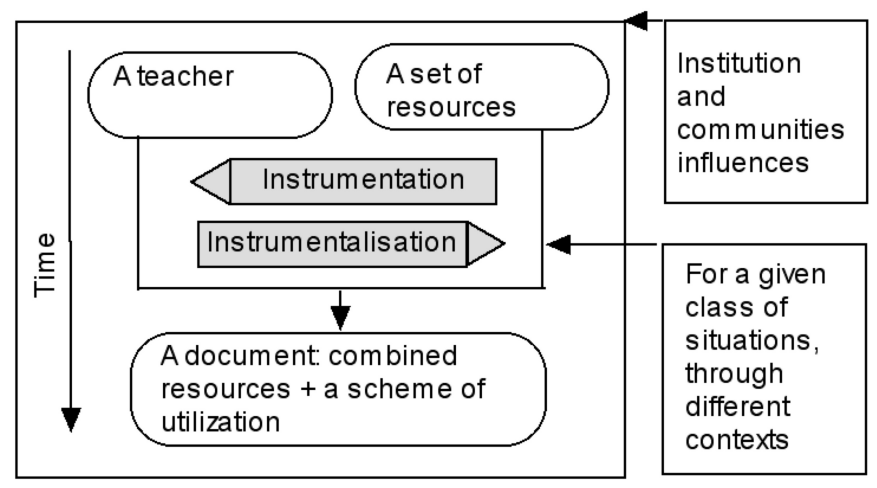

Figure 2. Schematic representation of a documentational genesis

The documentational genesis jointly develops a new resource (made up of a set of resources selected, modified, recombined) and a scheme of utilisation of this resource (see examples $\S 4.4$ ). We can represent, in a very simplified way, this process by the equation: Document $=$ Resources + Scheme of utilisation. A scheme of utilisation integrates practice (how using selected resources for teaching a given subject) and knowledge (on mathematics, on mathematics teaching, on students, on technology). A scheme combines elements of stability ('for teaching this subject, I use to...') and of evolutions (for adapting to new context łnew resources, new curriculum...).

A documentational genesis develops in a field of interactions: interactions between teachers and resources (instrumentalisation vs. instrumentalisation), interaction between teacher and students, interactions between teacher and colleagues. This last kind of interactions is certainly to be nowadays carefully considered: digitalization gives new occasions (emails lists, blogs, distance platform...) for communicating and sharing resources with colleagues. The frame of community of practice (Wenger 1998) appears thus relevant to describe new forms of teachers' engagement for common projects, resulting in shared resources.

Finally, the documentational approach gives new means for thinking teachers' development through their documentational work, individual as well as collective (Gueudet \& Trouche 2009b). It allows to reformulate the question at stake in this article: what are the effects of a collective documentation work, organized in the frame of a DGE in-service training device, on the practice and knowledge of the trainees?

\footnotetext{
${ }^{4}$ For example, it is possible to have access from any connected computer to free DGE online, to websites offering examples of use, mathematical problems, suggestions of solutions, etc. The hardware seems transparent; software and situations of use appear as merged.

${ }^{5}$ We have chosen the word 'document" to match the vocabulary of the document engineering (Pédauque 2006), a document including usages (effective or intended).
} 
Gueudet, G., \& Trouche, L. (2011). Mathematics teacher education advanced methods: an example in dynamic geometry. ZDM, the international journal on mathematics education, 43(3), 399-411.

\subsection{Needs for rethinking research methodology}

Considering teachers' development through the magnifying glass of their documentational geneses has deep methodological consequences, that we summarize around three principles:

- The reflexive investigation principle: understanding long-term processes as documentational geneses implies long-term follow-up, in and out-of-class, allowing distinguishing, within a teacher's documentation work, regularities and deep evolutions on the one side, and seeming variations on the other side. This necessary long and continuous follow-up led us to design tools for reflexive investigation (Gueudet \& Trouche, to appear), calling up the teacher's look on her own work, along a three weeks period: a logbook fulfilled by the teacher herself (describing her documentation work), the gathering of her resources, interviews and classrooms observations;

- The design-in-use principle (Rabardel \& Bourmaud 2003): any resource evolves through usages, along instrumentalisation processes (§ 2.1). Following the documentational approach, appropriating a resource is encapsulating in it something of her own experience and expertise. Therefore analysing the springs of a teacher's documentation work - and her knowledge in progress - implies to follow her creative work on resources, i.e. the process encompassing phases of design and phases of usage;

- The collective principle: a documentation work is never isolated. Understanding this documentation work requires to exploit the interrelations between peers within different collectives that a teacher is part of.

These principles frame our research methodology. They can also be considered as principles for the design of a teacher training program: a training should support a reflexive stance (and the reflexive stance in our methodology can contribute to teacher development, albeit we do use it with this aim); a training organised several times should evolve between each new implementation, incorporating necessary changes evidenced by its use; it would also gain of exploiting the potential of collective documentation.

In the next section we present an innovative teacher training program, which follows these principles. However we do not focus here on the "design" aspect of the corresponding project, but on the consequences of the training on the trainees documentation. This training program constitutes a good 'terrain' for exploiting our theoretical approach, and allowing to give some elements of answer to our research questions.

\section{An innovative teacher training program supporting ICT integration}

In this section, we present the French teacher education program Pairform@nce, the research that we are conducting in this context, and we focus on a training path dedicated to DGE.

\subsection{The French national program Pairform@nce, and the associated research}

Pairform@nce ${ }^{6}$, aiming to develop in-service teachers' skills in using ICT in class, proposes training paths for all topics, from primary to secondary school levels. This program lies on three main principles, in the thread of other innovative devices linked to research programs (§ 2.1):

(i) Articulating design of resources with ICT and implementation in class: a teachers' development program cannot be an only an out-of-school training, it necessarily implies experimentation of resources on the field and an afterwards reflection;

(ii) Favouring collaboration among teachers: professional development, especially concerning ICT, cannot only be an individual process; it results from the collective activity and experience within peers communities;

(iii) Maintaining the conditions of a continuous documentation work: working efficiently on resources needs maintaining an ongoing collaboration, intertwining face-to-face and on-line activities.

These training paths are available on an online platform (http://national.pairformance.education.fr/), each one dedicated to a given teacher training subject. Each path is structured in seven stages, that combined face-toface and distance work: 1) Introduction to the training session, 2) Selection of teaching contents and organisation of teachers teams, 3) Collaborative and self-training, 4) Collaborative design of a lesson, 5) Test of this lesson in each trainee's class, 6) Shared reflection about feedbacks of class tests, 7) Evaluation of the training session. Each stage comes with specific training resources, suggestions for teachers' activities and collaboration tools. These training paths have been elaborated by designers, which are most of the time expert teacher trainers. Once a training path is available on the platform, it can be chosen by teachers' trainers for setting up sessions for trainees. Thus, the Pairform@nce program involves multiple agents, at

\footnotetext{
${ }^{6}$ The word "Pairform@nce" is a modification of the French word "performance", where the first part "per" has been replaced by the word "pair". Per and pair have the same pronunciation in French but "pair" means peer. An English translation could be "PeerTr@ining", pointing out the principle of collaboration among teachers, @ standing for distance communication.
} 
Gueudet, G., \& Trouche, L. (2011). Mathematics teacher education advanced methods: an example in dynamic geometry. ZDM, the international journal on mathematics education, 43(3), 399-411.

least three levels of documentation work: the path designers, the teacher trainers and the teacher trainees. This program thus constitutes a very rich field of experiment for researchers whose theoretical background is the documentational approach. Therefore we have constituted a research team on Pairform@nce, made of six researchers in education (mathematics, geography and biology education), and 6 associated teachers trainers based in three academic regions (Lyon, Montpellier and Rennes) ${ }^{7}$. It has been associated since its beginning to this program, in a design experiment perspective, i.e. with "both a pragmatic bent - "engineering" particular forms of learning-and a theoretical orientation-developing domain- specific theories by systematically studying those forms of learning and the means of supporting them" (Cobb et al. 2003 , p. 9). We have followed the development of Pairform@nce, providing this program with tools, methods and recommendations and have examined several questions since 4 years, regarding the designers, the trainers and the trainees. We focus here on the trainees ${ }^{8}$, analysing their collective involvement in a training path dedicated to DGE, their documentation work and its effects on practice and knowledge. For this objective, we have applied the methodology already introduced (§ 2.3). This DGE path has been designed by teachers' trainers associated to our research team; we present its theoretical assumptions in the next section.

\subsection{Inquiry-based approach and the use of DGE in mathematics}

The precise title of the training path is (figure 3, our translation): "Design and implementation, in a computer lab, of practical work in a DGE "9. The presence, in this title, of practical work and of computer lab evokes the metaphor of mathematics laboratories, metaphor always active (Maschietto \& Trouche 2010) as soon as one wants to promote mathematical engagement to problem solving, for teachers and for students.

This path has been elaborated in 2007-2008 by a design group gathering teacher trainers, experimented both in training about DGE and in distant training (they have all been members of the SFoDEM, § 2.1). Its objective is introduced from the first lines: "Mathematics curriculum more and more often emphasizes the experimental dimension of mathematical activity and the helpful potentialities of DGE for the effective implementation of inquiry practices into the classrooms [...] The objective of this path is to support you, faceto-face, and at distance, in the collaborative design of practical work in a DGE". This objective justifies that we designate this path under the label "Inquiry with dynamic geometry" (IDG).

What is inquiry in mathematics has been extensively discussed since the beginning of the 1990s, following in particular the publication in the United States of the National Council of Teachers of Mathematics Standards (NCTM 1989). We retain here the definition of inquiry given by Fuglestad (2007, p. 1410): "Inquiry means to ask questions, make investigations, acquire information or search for knowledge and 'dialogic inquiry' furthermore willingness to wonder, seek to understand by collaborating with others". In the context of mathematics teaching with a DGE, it can be interpreted as giving responsibility to students, towards both the mathematics content and the DGE.

We will not detail here all the links between DGE and investigation in mathematics, but only mention some possibilities which have been considered by research works.

The direct manipulation, crucial feature of a DGE (§ 1), means simultaneity between students' action and DGE feedback. For Leung (2003), this simultaneity is a promising agent for bridging the gap between experimental and theoretical mathematics, or the transition between the processes of conjecturing and formalizing. Laborde (2001) illustrated this power, for the teaching of geometry, with the example of the "black-box" situations:

«In the black box situations, the students are given a diagram on the screen of the computer and they are asked questions about it. This kind of situation was used in our scenarios for introducing new transformations. A point $P$ and its image $P^{\prime}$ through the unknown transformation were given to the students. They could move $\mathrm{P}$ and observe the subsequent effect on $\mathrm{P}^{\prime}$. Students were asked to find the properties of the unknown transformation by means of this black box. In such a task, students must ask themselves questions about the transformation »

This description is consistent with the definition of inquiry we retained; it clearly emphasizes the responsibility of the students, who formulate questions about a transformation instead of following a presentation of its properties. Laborde (ibidem) also observes that such tasks, leading to reconsider the mathematics involved, is not easily proposed, even by teachers experienced in the use of DGE.

The potential of DGEs for inquiry is not limited to the field of geometry. In precalculus, DGE can also be used to introduce the notion of function (Falcade, Laborde \& Mariotti 2007): the dragging tool, for example, can

\footnotetext{
${ }^{7}$ Several institutions were involved in the research, particularly the INRP (French National Institute for Pedagogical Research), two IREM (Institute for Research on Mathematics Teaching) and one IUFM (Academic Institute for Teachers Education).

${ }^{8}$ For some results about designers and trainers, see Gueudet et al. (2009).

${ }^{9}$ A presentation of the path can be found at http://national.pairformance.education.fr/course/view.php?id=151 (visited September 1 , 2010).
} 
Gueudet, G., \& Trouche, L. (2011). Mathematics teacher education advanced methods: an example in dynamic geometry. ZDM, the international journal on mathematics education, 43(3), 399-411.

support the development of a feeling of functional dependency. Geometrical situations and functions can also be associated in specific problems, where DGE can be used for "the visualization of the dynamic aspect of functional dependencies simultaneously in different representations and offering opportunities to experiment with them" (Hoffkamp 2010, p.1201). We will consider such uses in the following section (§ 4).

For teachers, using a DGE in an inquiry perspective implies a double difficulty: they have to master both the mathematics at stake and the DGE, and face the DGE instantaneous answers (§ 2.1). The objective of the IDG path is to help teachers in overcoming this double difficulty, in the Pairform@nce spirit, i.e. via a collaborative design of resources. It is interesting to notice that the first innovative teachers' training program, based on the same spirit, that we have evoked, also focused on "inquiry-based geometry in school classrooms" (Allen et al. 1992). We hypothesize that this coincidence is not fortuitous: supporting teachers in the complex mastering of inquiry-based teaching in their classrooms requires the strong strings of collective documentation processes.

\subsection{The IDG path: presentation and implementation}

In 2008-2009, training programs built on this path have been organized in the academy ${ }^{10}$ of Montpellier and in the academy of Rennes, by trainers who were not its initial designers. These trainers adapted the path to their own needs; they also sent, after the training, remarks and suggestions to the initial designers, who decided to integrate some of these, and to reject others, following a design-in-use principle (§ 2.3). The path that we briefly describe here corresponds to the version adapted by the trainers of Rennes, and used for trainings in 2008-2009 and 2009-2010 ${ }^{11}$.

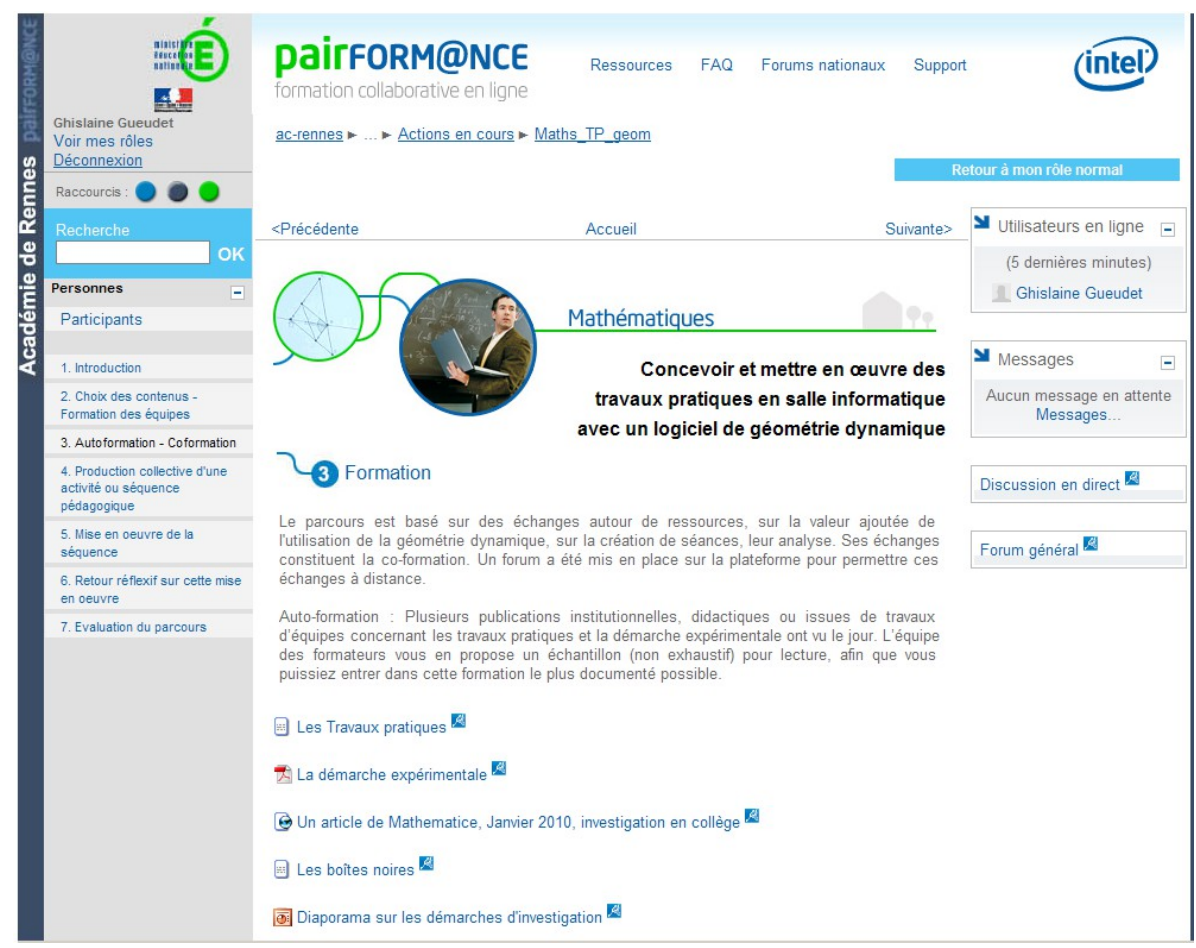

Figure 3. Extract of the IDG path (stage 3) used in the academy of Rennes in 2009-2010.

The training, following the seven Pairform@nce stages (§. 3.1), takes place during 13 weeks (outside holidays); it comprises three face-to-face workshops of one day each. Between these face-to-face meetings, a continuous work is done, using the email, and the training distant platform. The trainees are lower secondary school teachers, teaching thus from grade 6 to 9. The DGE used in the path are GeoGebra ${ }^{12}$ and Tracenpoche $^{13}$ (for legal reasons, all the software used in the Pairform@nce paths must be under free licence).

\footnotetext{
${ }^{10}$ In France the educational policy is decided at the national level. Nevertheless France is splitted in "academies": regions, with a local authority implementing the policy.

${ }^{11}$ The initial designers of the path, in Montpellier, are: B. Clerc, J. Haraki, N. Moreau \& J.-M. Ravier.(2007); the designers-in-use, in Rennes, are F. Loric, H. Hili \& G. Gueudet.

12 http://www.geogebra.org/cms/

${ }^{13}$ http://tracenpoche.sesamath.net/ Tracenpoche is designed by a French online association of mathematics teachers, Sesamath.
} 
Gueudet, G., \& Trouche, L. (2011). Mathematics teacher education advanced methods: an example in dynamic geometry. ZDM, the international journal on mathematics education, 43(3), 399-411.

The training starts with an email contact, one week before the first face-to-face workshop. The trainers send attached to this email a first questionnaire for the trainees. This questionnaire permits to collect the trainees expectations, to get information about the material they can use in their school, and about their ideas and experiences about both inquiry in mathematics and DGE.

During the first workshop, the training is presented, the trainees teams are constituted. The teams, if possible, comprise 4 teachers: 2 from one school, and 2 from another school. This way, the teachers easily meet by pairs; but they are also obliged to use distant communication, via the platform. This should ensure the regular connection to the platform, necessary to see the resources proposed by the trainers.

We use here the following vocabulary (according to the choices made in the path): a scenario is the description of a teaching. Sometimes it corresponds only to a planned teaching, which does not necessary lead to a classroom implementation ${ }^{14}$. The actual classroom implementation is called a lesson; a scenario can also be the description of a lesson, following the effective classroom implementation. Moreover, when we refer to a mathematical text, without indications of use (an exercise in a textbook, a problem elaborated by the teachers etc.), we call it here a problem text.

The trainers present during the first workshop two examples of scenarios, corresponding to very different uses of a DGE. The first example corresponds to a more "classic" one: introduction of a new notion (the triangle area), the DGE is used to build a dynamic figure, then to formulate a conjecture by dragging the figure; a paper-and-pencil proof follows. The second example is of black-box type ( $\$ 3.2$ ): a diagram is provided, with a triangle and a point (resulting from a hidden construct); the students have to find how the point has been constructed, how it is linked with the triangle. These contrasted examples permit to start a discussion that goes on during the whole training, questioning important aspects of inquiry in mathematics, and of the possible role of a DGE:

- How is it possible to articulate inquiry, and the usual curriculum? How to avoid "loosing time", regarding the mathematical content to be taught?

- What can be the role of a DGE for inquiry? The students can certainly use dynamic figures to formulate conjectures, but is it possible to go further? Can the DGE intervene also in the modelling of a situation, or even in a proof?

- More generally, which can be the link between inquiry and proof, is there a risk that inquiry hinders the learning of mathematics?

The scenarios presented during this first workshop also permit to present three grids, which will be used during all the training: grid for the presentation of a scenario; grid for observation of an inquiry-oriented session with dynamic geometry; grid for final report and suggestions about the lesson.

At the end of this first workshop, two problem texts are proposed by the trainers. Each team will have to choose one of these texts, and build a scenario for its implementation in class, with an inquiry-based approach. This scenario is designed between the face-to-face workshops 1 and 2 . Two functionalities of the platform are especially designed for the distant communication during this work: a specific forum, and a folder for exchanging files. The trainers support this distant work, but do not try to influence the decisions of the team.

During the second workshop, the scenarios proposed by the teams are presented and collectively analysed. Does the scenario organise the students' construction of an experiment? Their manipulation of a dynamic diagram for formulating conjectures? The test of these conjectures? The search for a proof? Does it plan collective discussions within the whole class? Comparisons between the different scenarios proposed for the same problem text enrich this discussion. Nevertheless, since these texts have not been chosen by the teachers, they do not correspond to what they are doing in class at that moment, and the scenarios do not lead to lessons in class.

After this discussion, the teams start the work on the themes they retained for the scenarios they will test in class. These scenarios are elaborated and tested between workshops 2 and 3 . Once again, a specific forum and a folder permit the distant communication within each team, and with a trainer who specially follows the team. A first version of the scenario is designed. The corresponding lesson is set up in class by one of the trainees; at least one other trainee observes the lesson and takes notes. After the first test and the observation, suggestions of improvements are formulated within the team. If possible, another test in class, incorporating the modifications, is organized. New suggestions of improvements are formulated. The description of the lesson, the observations, the suggestions for improvement are uploaded on the platform, in a folder shared by all the trainees and trainers, at least one week before the last workshop. During the third face-to-face workshop, the scenarios are discussed, and propositions of further improvements are

\footnotetext{
${ }^{14}$ A didactical performance, as Drijvers et al. (2010) define it, but we avoid here this vocabulary which can be ambiguous in the case of Pairform@nce!
} 
Gueudet, G., \& Trouche, L. (2011). Mathematics teacher education advanced methods: an example in dynamic geometry. ZDM, the international journal on mathematics education, 43(3), 399-411.

formulated.

According to our theoretical approach ( $\S 2.2$ ), such a work is likely to yield documentational geneses, thus, in particular, evolutions of the teachers practices. Naturally, geneses are long-term processes; even the thirteen weeks of the training can only initiate a genesis. We followed in 2009-2010 two trainees, in order to investigate precisely such geneses, or beginning of a genesis.

\section{Inquiry with dynamic geometry and documentational geneses: a case study}

We followed more closely, in 2009-2010, two trainees, Lauren and Gilda, participating to the IDG path. Lauren and Gilda designed and implemented a scenario for grade 9 (Gilda implemented it twice, with two half-classes). They retained, as a starting point, an optimization problem, to be studied with GeoGebra. We present first our methodology for this follow-up and for the analysis of the data gathered. Then we present an analysis of the potential use of GeoGebra for studying this situation with the students. We give at last a short account of the lessons resulting from the scenarios, before studying the attached documentational geneses.

\subsection{Methodology}

All the Pairform@nce trainings that we organized were associated with data collection, drawing on the very features of Pairform@nce. The trainees fill two questionnaires, at the beginning and at the end of the training. Their exchanges on the several forums of the platform, all the files they upload are collected: in particular, the scenarios, the filled observation grids and report grid.

In 2009-2010, we followed more precisely two trainees, who volunteered to participate to the research. These trainees filled, during all the training, a logbook, noting their activity related with the training: during the workshops, during the lesson in class, but also all the preparation activity. We observed and videotaped one of the lessons, made by Gilda in her grade 9 class. After this implementation, we met Lauren and Gilda for an interview about the training and about their lesson. We also collected all the resources they used in their preparation. This data collection follows the "reflexive investigation" principle (§ 2.3). The reflexive view of the trainees on their own activity is mobilized, when filling the logbook, and in the interviews.

For organizational reasons, it was not possible to observe the trainees before the training (their names being known only at the last minute). Thus we partly rest on their declarations, to identify the changes brought by the training.

In this article, we focus on geneses attached to precise uses of GeoGebra. We draw on all the data gathered: the resources used to prepare the lesson, the video of the lesson, the interview and the logbooks, the description, observation and report grids filled about the lesson. We start with an analysis of the possible choices for the scenario (see section 4.2 below). It grounds our analysis of the actual choices; we search then, within the data, for elements enlightening these choices, either as evolutions, or as stabilities. For the evolutions, we investigate the possible role of the training.

Our approach shares similarities with the one developed by Laborde (2001) to study the integration of DGE, who proposes to "reconstruct the choices of the teachers underlying the design of the teaching sequences based on the use of technology and their evolutions; from these choices [..] infer their conceptions about the nature of mathematical activities and about learning mathematics." The reconstruction of choices, in our case, in grounded in a large variety of sources: questionnaire, logbook, classroom videos, interview, files and discussions on the platform etc. Moreover, the inference following this reconstruction takes the particular form of inference of schemes (§ 2.2).

\subsection{Optimization with GeoGebra: analysis of potential uses}

The optimization problems we consider here, in the context of the French national curriculum for grade 9 , are presented as "real life" problems, where a maximum or minimum must be determined under given constraints.

The "real life" situation can be modelled in geometry; the value to maximize or minimize is a geometrical measure: area, perimeter, angle, depending on another measure. The situation can also be modelled with a function, which is most of the time a polynomial of degree two. At grade 9 in France, the students discover the notion of function; they do not learn techniques to determine the extreme value of a degree two polynomial, but can solve a guided exercise about this topic. The exercise retained by Lauren and Gilda (figure 4) is of this kind. 
Gueudet, G., \& Trouche, L. (2011). Mathematics teacher education advanced methods: an example in dynamic geometry. ZDM, the international journal on mathematics education, 43(3), 399-411.

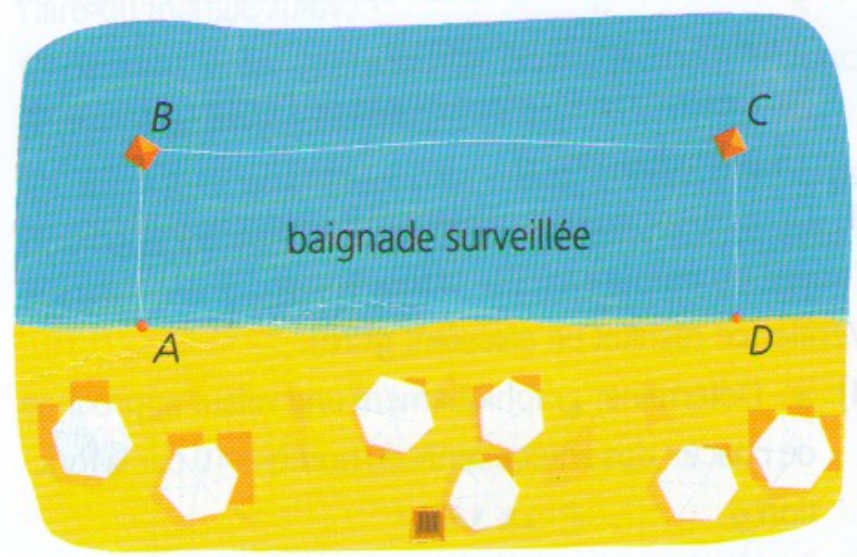

A lifeguard uses a rope and two buoys ( $B$ and $C$ ) to form the boundary of a swimming zone. He forms this way a rectangular zone. The length of the rope is $160 \mathrm{~m}=16 \mathrm{dam}$. He wonders where to place the buoys $B$ and $C$ to obtain a swimming zone with the largest possible area. The point $A$ is fixed.

Figure 4. Diagram of the 'swimming zone', problem retained by Lauren and Gilda's team.

We do not intend here to make an exhaustive analysis of all the possible uses of a DGE for such a problem; we only want to point relevant dimensions of analysis, in an inquiry perspective teaching ( $\$ 3.2$ ), focusing on the respective students' and teacher's roles, regarding the mathematical content and the DGE.

As mentioned above, two main possibilities of modelling appear: one with a geometric construction, the other with a function. In both cases, the modelling can be associated with the use of a DGE.

For the geometric construction, the students have to build a rectangle $A B C D$, respecting the length constraint: $A B+B C+C D=16$ (we consider here the decametre as the length unit). This can be done with coordinates, or only by using perpendiculars, for the right angles, and a circle to respect the length constraint. A is fixed; as soon as another point is chosen ( $B$ for example), the rectangle and its area are determined. The area of the rectangle can be displayed on the DGE; the free point can be dragged, the students can observe the area variations, and notice that 32 seems to be the maximum value, observed for a 4 over 8 rectangle. Either with coordinates, or with a circle, the students have to notice that $A B=C D$ (property of the rectangle), and thus $B C=16-2 A B$. This can be associated with an algebraic modelling: $A B$ can be labelled as $x$, which gives $B C=16-2 x$. GeoGebra, labelling all the objects with a single letter, influences such an algebraic formulation of the geometric modelling.

The modelling with a function is somehow a second step, because it requires first to use the rectangle (but this can be limited to a paper-and-pencil stage). Extending the reasoning evoked above, the students can write the area as a function $a$ of the length $A B=x$, defined by $a(x)=x(16-2 x)$. The graph of this function can be constructed with GeoGebra, and the coordinates of the maximum identified by a graphical reading.

The geometrical and functional modelling can also be associated (figure 5): once the rectangle is constructed, a point $M$, whose coordinates are the length $A B$ and the rectangle area, can be created. Activating the trace of point $\mathrm{M}$, and dragging the free point $\mathrm{B}$, creates a cluster of points, belonging to the graph of the function a (which can stay implicit or not). Then the same graphical reading can be done to find the maximum. 
Gueudet, G., \& Trouche, L. (2011). Mathematics teacher education advanced methods: an example in dynamic geometry. ZDM, the international journal on mathematics education, 43(3), 399-411.

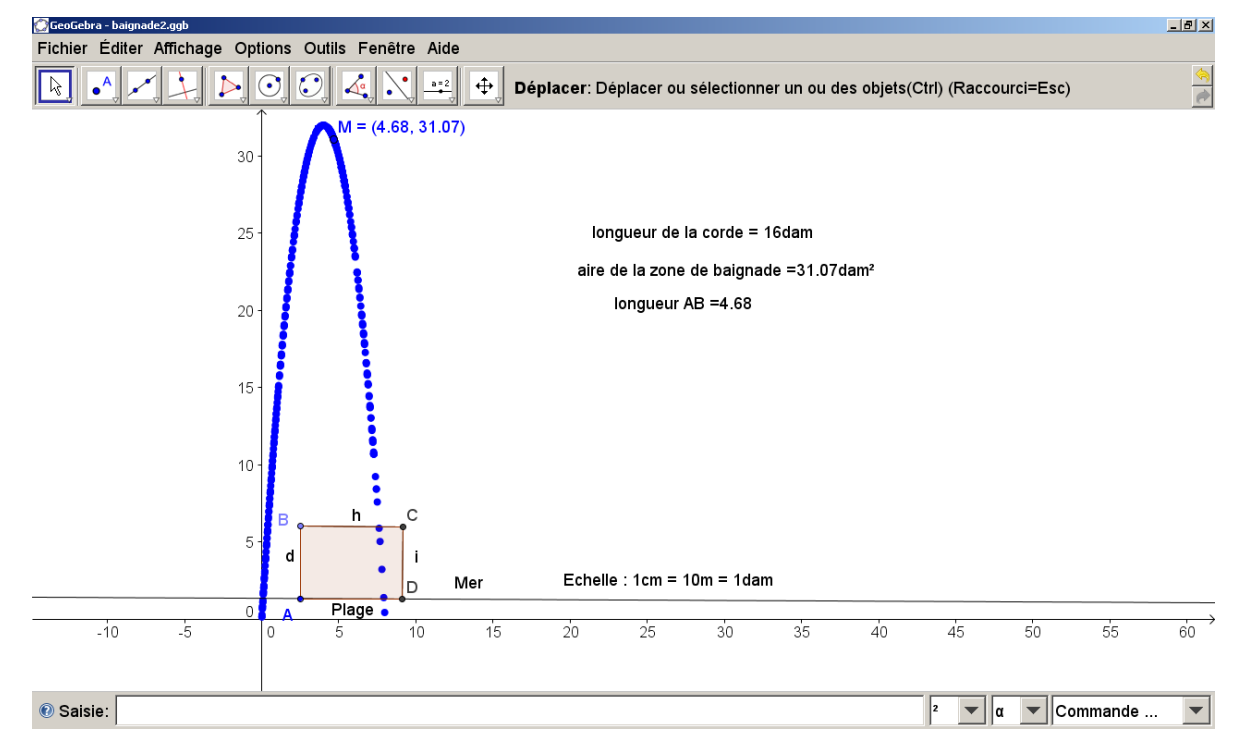

Figure 5. Use of GeoGebra to represent the 'swimming zone' situation, with a rectangle and the trace of a point.

In both cases, the dynamic construction, the dragging, the observation can be completely under the responsibility of the students, or under the teacher's responsibility, with all the intermediate steps between these two extreme possibilities.

Many other choices of the teacher are important, for the orchestration (§ 2.2) of this situation: the presence, or not, of a final work about the associated proof; the articulation between the software and paper-and-pencil work. We can notice that, for this problem, the conjecture (the value of the maximum is 32 , and is obtained for a rectangle of size 4 over 8 ) involving 'simple' numbers, is easily found on paper and pencil. The interest of the other procedures is more attached to the geometrical, algebraic or functional modelling. The role of the DGE can also be to induce these modellings, and to evidence the different possible modellings of the situation.

\subsection{Scenario and lesson}

During the training, Lauren and Gilda were in a team with two colleagues from another school. The team retained the problem text mentioned in figure 5 , found in a textbook, during the second workshop. During this workshop, the team started to transform the text, and to think to a scenario involving GeoGebra and a spreadsheet. Unfortunately the two other colleagues were not familiar with the use of the platform and distant communication. After the second workshop, the scenario was designed by Lauren and Gilda without any collaboration with their colleagues. Lauren and Gilda worked together by email. Gilda started by writing the first draft for a sheet to be distributed to the students and filled by them in class; and a first draft of the scenario. Lauren suggested adaptations.

The scenario designed started with a homework: drawing the graph of the function $f$ defined by $f(x)=16 x-2 x^{2}$, for $x$ belonging to the interval $[0,8]$. This homework was followed by a work in five parts: a paper-and-pencil work, each student draws a line corresponding to the situation, the area of the corresponding rectangles are compared, leading to a first hypothesis. Then the hypothesis is formulated again with three other strategies:

- With GeoGebra and a geometrical modelling: a file including a line (the limit of the sea) with point $A$ is given, they build point $B$ with a perpendicular, and create the segment [AB]. This segment is labelled $d$; then point $C$ is created with a perpendicular and a circle of centre $B$ and radius $16-2 d$, and the figure is completed with point $D$, and the creation of the rectangle. The area is displayed; students drag point $B$ and observe the maximum value obtained for the area. All the steps of the construction are indicated on a student's sheet (figure 6).

Open the file 'swimming.ggb', and save it in your folder with your names. Follow the construction program:

1. Create the perpendicular through $A$ to the water limit,

2. Create a free point $B$ on this perpendicular, display its label,

3. Create the perpendicular to $(A B)$ through $B$,

4. Create the segment $[A B]$, rename it and display its label as $d$, if necessary. $d$ corresponds to the 
Gueudet, G., \& Trouche, L. (2011). Mathematics teacher education advanced methods: an example in dynamic geometry. ZDM, the international journal on mathematics education, 43(3), 399-411.

- distance $A B$.
5. Create the circle with centre $B$ and radius $16-2 d$, explain the link with point $C$ position:
7. Move the point $B$ and observe what happens:
and display its label.

Figure 6. Extract of the student's sheet, beginning of the work with GeoGebra (our translation). Question 6 in italics has been added between the first and the second realization.

- With GeoGebra, the geometrical modelling, and the trace of the point $M$ whose coordinates are $d(=A B)$ and the area. In this case the file (figure 5) is given to the students who do not construct but manipulate and observe the maximum of $\mathrm{M}$ y-coordinate. A link is made with the graph proposed for homework;

- With Open Office Calc and an algebraic modelling. The students fill a sheet with two columns: one with values between 0 and 8 , the other with the corresponding values of the area.

Finally a guided proof is proposed, the students must look for the proof and write it on a paper.

Gilda and Lauren plan two hours for the whole lesson in Gilda's class. It is set up twice, with two subgroups: Gilda's grade 9 class has 30 students, and the computer lab is a small room, with only 10 computers. The first subgroup comprises 12 students, encountering no difficulties in mathematics. The students go through the whole activity, but, according to Gilda (interview and logbook) and to Lauren (observation notes and logbook), they have difficulties to connect the initial situation and the successive steps. The lessons of the two subgroups are separated by two days, during which Gilda changes the student sheet, to evidence more the fact that "when B is chosen, the whole figure is determined", essential according to her to understand the situation and connect the different parts of the lesson. With the second subgroup (some of them very lowachieving in mathematics), difficulties arise early because several students do not master GeoGebra. These students worked on GeoGebra the previous year; this year, Gilda used GeoGebra to illustrate her course, but the students are for the first time using it themselves. Thus Gilda has to recall the functionalities of the software and the related icons. She is finally obliged to cancel the spreadsheet part, which is proposed as homework.

\subsection{Lauren and Gilda documentation work and geneses}

Lauren and Gilda, as trainees in the Pairform@nce program, developed a documentation work involving many resources: a textbook (not the usual class textbook), GeoGebra, a spreadsheet, the email to communicate etc. Several geneses are attached to this documentation work, yielding practice evolutions.

Gilda teaches in lower secondary school for only two years; she has been before, during four years, a teacher in an upper secondary school with almost no available computers. It is the first time that she designs a whole scenario for the computer lab; usually she downloads scenarios on the Internet, or finds them in books, and only realises limited adaptations. The training led her to realize this first 'complete' design. Lauren is working at this level for eight years, and is more experienced in the design of computer sessions. She was interested in evolving towards scenarios where the computer is not the aim of the activity, but a tool to practise mathematics. She considers that the training contributed to this ongoing evolution. These evolutions are important consequences of the training; however, they are too general to be interpreted in terms of geneses and documents. We will now focus on geneses corresponding to precise mathematical contents and functionalities of the DGE.

Inquiring measures evolutions

Gilda and Lauren declare in their interview and their questionnaires that they retained the training for two main reasons: the collective work, that they wanted to develop in the team of mathematics teachers in their school; and the inquiry with software, which corresponds to institutional expectations. Gilda bought at the beginning of the year a book about inquiry with software, proposing scenarios for grade 8 (Rouquès \& Staïner 2009), and uses it to prepare grade 8 lessons with GeoGebra. Considering the choices they realized for the lesson presented above, the inquiry dimension can seem limited, since the use of the DGE is closely guided. The successive steps of the construction are given on the sheet; the dragging of point $B$ on the dynamic diagram is also indicated. The students' responsibility is more important in the observation dimension: dragging point $B$ has several consequences; the students have to select which consequence to focus on, and to formulate their observation.

This kind of observation of a numerical value evolutions, when dragging a point in a dynamic figure, followed 
Gueudet, G., \& Trouche, L. (2011). Mathematics teacher education advanced methods: an example in dynamic geometry. ZDM, the international journal on mathematics education, 43(3), 399-411.

by the formulation of the observation, and leading in some cases to the formulation of a conjecture is present in several productions of Gilda and Lauren. It appears in the problem text they prepared during the training between workshop 1 and 2 (looking for a minimal distance), the lesson discussed here, and a lesson that Gilda set up afterwards about the 'angle at the centre' theorem. These different observations lead us to consider that Gilda and Lauren developed a document, for the class of situations 'designing and implement a problem about measures properties'. This document includes recombined resources: a DGE, a mathematical text; we infer that it also a rule of action like 'a DGE can be used to help the students to observe properties of measures', associated with an operational invariant like: 'Numerical values evolving with the dynamic values on a DGE permit to observe properties of measures of a geometrical figure'. The development of this document probably started before the training. When Gilda and Lauren started it, they already developed knowledge about the use of a DGE for the formulation of hypotheses by the students. This knowledge guided their choices in the design of this lesson, in an instrumentalisation process. Their documentation work during the training also contributed to a further step in this long-term process, a further evolution of this knowledge, which will certainly go on after the training.

Articulating different dynamic representations to support the learning of functions

Another important point for Gilda and Lauren in this lesson is proposing to the students to work with different representations, evidencing functional relations. In fact the use of GeoGebra seems mostly directed towards evidencing functions as processes, enhancing dynamic aspects of functions through the different representations allowed by the software, and connecting these representations (Hoffkamp 2010). During her observation of the implementation with the first half-class, Lauren notes, in the observation grid $(\S 3.3)$ and in her logbook, that the students have difficulties to connect the different representations proposed in the lesson. Discussing via email with Gilda, they identify that a central issue, for the problem and for establishing connections between the different representations, is that the students notice that when $B$ is fixed, there is no choice left for the rest of the figure. Gilda introduces question 6 (figure 6), expecting the students to answer that when $B$ is dragged, the radius of the circle evolves. Indeed with the label $d$ used for the distance $A B$, the students can miss the connection between $B$ and the radius of the circle (naturally, when $B$ is dragged the centre of the circle moves as well, but Gilda does not expect this answer). She also asks the students to observe how the rectangle, and then its area, change. In the following section, she asks to observe the 'numbers placed in the parentheses' next to point $M$ and their evolution; then she asks the students to connect the trace of $M$ and the graph of the function $f$ proposed for homework. The trace of the point $M$ (figure 5) is a dynamic representation, changing each time that $B$ is dragged. It is connected on the one hand with the dynamic diagram of the rectangle, each position of the point $\mathrm{M}$ corresponding to one rectangle; on the other hand with the static graph of the function that the students drew on a paper. This last connection is linked with a discretization of the graph, as a set of points; it confers to the graph a dynamic aspect, as being progressively constructed as a cluster of points. In this case, we consider that Gilda started to develop a document, for the class of situation: "Designing and setting up the introduction of the notion of function". We infer from the different elements described that this document entails, in particular, operational invariants like 'students need to connect several representations to discover the concept of function'; 'dynamic representations help to build the idea of function as a process'; 'a DGE permits to elaborate different dynamic representations and to connect these representations'. One of the problems proposed for building scenarios between the first and the second workshops was quite similar to the 'swimming zone' situation (maximizing the area of a rectangle inscribed in a square-angled triangle). The trainers proposed during the second workshop, for this problem, a scenario using a DGE with the geometric figure, and the trace of an associated point. Gilda and Lauren did not download this example on the platform, but they appreciated it during the workshop. An instrumentation process, consequence of the use of this resource during the training, probably contributed to the emergence of this document. It is certainly also a consequence of the features of the software used, an instrumentation process linked with the possibilities of representation offered by GeoGebra.

\section{Avoiding the use of coordinates}

Confronting Gilda's and Lauren's choices to the analysis of potential uses presented above evidences the facts that we already mentioned: the inquiry is limited to observation of measures evolutions; the different dynamic representations are articulated, to support the learning of functions. It also evidences that Gilda and Lauren seem to avoid the use of coordinates. All the points, in the first GeoGebra file, must be constructed using geometrical objects: perpendiculars, and a circle. The following excerpt of the lesson, about the construction of point $\mathrm{C}$ confirms this hypothesis:

Gilda: Which is the geometric tool permitting to build a point at the right distance [from point B]?

Student: The input field?

Gilda: No, not the input field. It will not be simple with the input field. 
Gueudet, G., \& Trouche, L. (2011). Mathematics teacher education advanced methods: an example in dynamic geometry. ZDM, the international journal on mathematics education, 43(3), 399-411.

The student intervening here was at ease with the use of GeoGebra. In fact he was representing the rectangle without reading the instruction sheet, which imposes the circle to build $C$. It would have been possible to build $\mathrm{C}$ with its coordinates, using the input field. But Gilda does not want to exploit this possibility. Moreover, in the two files she prepared for the students, the algebra window is hidden. Gilda only started to use GeoGebra the year before; she was accustomed to use Geoplan before. According to GeoGebra designers: "The most remarkable feature of GeoGebra is the dual view of objects: every expression in the algebra window corresponds to an object in the geometry window and vice versa" 15 . Gilda did not yet start to develop documents including this feature. This might be related with the class level: in grade 9 , students are not yet very familiar with coordinates. However we hypothesize that it is more a consequence of her experience with Geoplan. She has developed operational invariants attached to the use of Geoplan, which has no algebra window or input field (points can be constructed from their coordinates in Geoplan, but it requires to open a specific window). These operational invariants (outcomes of the instrumentation attached to her use of Geoplan) intervene in her documentation work, even with a new DGE, yielding a form of inertia; it appears as consequence of the curriculum script, a loosely ordered model of relevant goals and actions, a key feature for technology integration, according to Ruthven (2009).

\section{Conclusion}

The IDG path of Pairform@nce shares with the Intergeo project the aim of supporting the integration of dynamic geometry, through the proposition of specific resources. In the case of Pairform@nce, the focus is on resources scaffolding the design of scenarios by teams of teachers with the support of a trainer. The training in presence also plays an essential role. The collective documentation work is the key feature retained in an objective of professional development. The implementation of the scenario, leading to an effective lesson, followed by a further evolution of the scenario is also a central characteristic of the training, corresponding to the design-in-use perspective.

The case study presented above evidences the fact that teachers following such a training do not necessarily design scenarios with an important inquiry part, drawing on all the possibilities offered by a DGE, during the training. However, we identified geneses, the beginning of the development of documents, which indicate evolutions in the teachers professional knowledge about DGE and inquiry. These geneses are long-term processes, they should not stop at the end of the training. The resources mobilized during the training, or designed by the teachers themselves remain available on their computers, interactions with these resources can go on the following year, all the more so pairs of teachers in the same school followed the training.

Following the teachers after the year of the training is naturally a perspective for our further work. The methodology presented here can be adapted to this new context, with a focus on the use of the resources coming from the training, in the frame of the methodological principles attached to the documentational approach. More generally, this reflexive investigation methodology, and the related theoretical approach, are still being developed, in particular about the issues raised by collective dimensions. What is the 'common part' of the individual documents generated by a collective work? To what extent is it possible to speak of a common knowledge coming from a community documentation genesis? Which methodological tools can contribute to answer these questions: a common logbook, use of videos for auto-analysis or cross autoanalysis ? These issues must still be studied, and probably require to draw on several approaches (Gueudet \& Trouche to appear).

\section{References}

Adler, J. (2000). Conceptualising resources as a theme for teacher education. Journal of Mathematics Teacher Education, 3, 205-224.

Allen, R., Wallace, M., Cederberg, J., \& Pearson, D. (1996). Teachers Empowering Teachers: VerticallyIntegrated, Inquiry-Based Geometry in School Classrooms, Mathematics Teacher 90(3), 254-255.

Artigue, M. (1998). Teacher training as a key issue for the integration of computer technologies, in J.D. Tinsley \& D.C. Johnson (eds.), Information and communication in school mathematics (pp. 121-129), Chapman and Hall.

Artigue, M. (2002). Learning Mathematics in a CAS Environment: The Genesis of a Reflection about Instrumentation and the Dialectics between Technical and Conceptual Work, International Journal of Computers for Mathematical Learning, 7(3), 245-274.

Cobb, C., Confrey, J., diSessa, A., Lehrer, R., \& Schauble, L. (2003). Design Experiments in Educational Research, Educational Researcher, 32-1, 9-13.

\footnotetext{
${ }^{15}$ GeoGebra quickstart guide, http://www.geogebra.org/source/translation/quickstart/.
} 
Gueudet, G., \& Trouche, L. (2011). Mathematics teacher education advanced methods: an example in dynamic geometry. ZDM, the international journal on mathematics education, 43(3), 399-411.

Drijvers, P., Doorman, M., Boon, P., Reed, H., \& Gravemeijer, K. (2010). The teacher and the tool: instrumental orchestrations in the technology-rich mathematics classroom. Educational Studies in Mathematics, online, http://www.springerlink.com/content/h05706778621581u/

Falcade, R., Laborde, C., \& Mariotti, M.A. (2007). Approaching functions: Cabri tools as instruments of semiotic mediation. Educational Studies in Mathematics, 66(3), 317-333.

Fuglestad, A.B. (2007). Developing tasks and teaching with ICT in mathematics in an inquiry community. in D. Pitta-Pantazi \& G. Philippou (eds.), Proceedings of the Fifth European Conference on Research on Mathematics Education. ERME, http://ermeweb.free.fr/CERME\%205/WG9/9_Fuglestad.pdf

Gueudet, G., Soury-Lavergne, S., \& Trouche, L. (2009). Soutenir l'intégration des TICE : quels assistants méthodologiques pour le développement de la documentation collective des professeurs ? Exemples du SFoDEM et du dispositif Pairform@nce, in C. Ouvrier-Buffet \& M.-J. Perrin-Glorian (dir.), Approches plurielles en didactique des mathématiques (pp. 161-173). Paris : Laboratoire de didactique André Revuz, Université Paris Diderot.

Gueudet, G., \& Trouche, L. (2009a). Towards new documentation systems for teachers? Educational Studies in Mathematics, 71(3), 199-218.

Gueudet, G., \& Trouche, L. (2009b), Teaching resources and teachers professional development: towards a documentational approach of didactics, in V. Durand-Guerrier, S. Soury-Lavergne, \& F. Arzarello (eds.), Proceedings of the Sixth European Conference on Research on Mathematics Education (pp.1359-1368), INRP www.inrp.fr/editions/cerme6

Gueudet, G., \& Trouche, L. (to appear) Teachers' work with resources: documentational geneses and professional geneses, in Gueudet, G., Pepin, B., \& Trouche, L. (eds.) Mathematics curriculum material and Teacher Development: from text to 'lived' resources. Springer.

Guin, D., \& Trouche, L. (1999). The Complex Process of Converting Tools into Mathematical Instruments: the Case of Calculators. International Journal of Computers for Mathematical Learning, 3, 195-227.

Guin, D., \& Trouche, L. (2002). Mastering by the teacher of the instrumental genesis in CAS environments: necessity of instrumental orchestrations, ZDM, The International Journal on Mathematics Education, 34(5), 204-211.

Hennessy, S., Ruthven, K., \& Brindley, S. (2005). Teacher perspectives on integrating ICT into subject teaching: commitment, constraints, caution and change, Journal of curriculum studies, 37(2), 155-192

Hoffkamp, A. (2010). Enhancing the functional thinking using the computer for representational transfer, in V. Durand-Guerrier, S. Soury-Lavergne \& F. Arzarello (eds.), Proceedings of the Sixth European Conference on Research on Mathematics Education (pp. 1201-1210), INRP, www.inrp.fr/editions/cerme6

Joubert, M., Back, J., De Geest, E., Hirst, C. \& Sutherland, R. (2009). Professional development for teachers of mathematics: opportunities and change, in V. Durand-Guerrier, S. Soury-Lavergne \& F. Arzarello (eds.), Proceedings of the Sixth European Conference on Research on Mathematics Education (pp. 1761-1770), INRP, www.inrp.fr/editions/cerme6

Kortenkamp, U., Blessing, Axel M., Dohrmann, C., Kreis, Y., Libbrecht, P., \& Mercat, C. (2009). Interoperable Interactive Geometry for Europe - First technological and educational results and future challenges of the Intergeo project, in V. Durand-Guerrier, S. Soury-Lavergne \& F. Arzarello (eds.), Proceedings of the Sixth European Conference on Research on Mathematics Education (pp. 1150-1160), INRP, www.inrp.fr/editions/cerme6

Krainer, K., \& Wood, T. (eds.). (2008). Participants in Mathematics Teachers Education: Individuals, Teams, Communities and Networks (Vol. 3). Rotterdam/Taipei: Sense Publishers.

Laborde, C. (1998). Vers un usage banalisé de Cabri-Géomètre avec la TI 92 en classe de seconde : Analyse des facteurs de l'intégration, in D. Guin, Calculatrices symboliques et géométriques dans l'enseignement des mathématiques (pp. 79-94). Montpellier: IREM, Université Montpellier 2.

Laborde, C. (2001). The use of new technologies as a vehicle for restructuring teachers' mathematics, in T. Conney \& F.L. Lin (eds.), Making sense of mathematics teacher education (pp. 87-109). Dordrecht: Kluwer Academic Publishers.

Laborde, C. \& Laborde, J.-M. (2008). The development of a dynamical geometry environment, in K. Heid \& G. Blume (eds.), Research on Technology and the Learning and Teaching of Mathematics, Vol. 2 Cases and Perspectives (pp. 31-52). Charlotte, NC, USA: Information Age Publishing.

Lagrange, J.-B., Artigue, M., Laborde, C., \& Trouche, L. (2003), Technology and Mathematics Education: a Multidimensional Study of the Evolution of Research and Innovation, in A.J. Bishop, M.A. Clements, C. Keitel, J. Kilpatrick, \& F.K.S. Leung (eds.), Second International Handbook of Mathematics Education 
Gueudet, G., \& Trouche, L. (2011). Mathematics teacher education advanced methods: an example in dynamic geometry. ZDM, the international journal on mathematics education, 43(3), 399-411.

(pp. 239-271). Dordrecht: Kluwer Academic Publishers,

Leung, A. (2003). Dynamic geometry and the theory of variation, in N.A. Pateman, B.J. Dougherty \& J. T. Zilliox (Eds.), Proceedings of the 27th PME International Conference, 3, 197-204.

Maschietto, M., \& Trouche, L. (2010). Mathematics learning and tools from theoretical, historical and practical points of view: the productive notion of mathematics laboratories. ZDM, The International Journal on Mathematics Education, 42(1), 33-47.

NCTM (1989). The curriculum and evaluation standards for school mathematics. Reston, VA: Author.

Pédauque, R. T. (coll.) (2006). Le document à la lumière du numérique. Caen : C \& F éditions.

Rabardel, P., \& Bourmaud, G. (2003). From computer to instrument system: a developmental perspective. In P. Rabardel \& Y. Waern (Eds.), Special Issue "From Computer Artefact to Mediated Activity", Part 1: Organisational Issues, Interacting With Computers 15(5), 665-691.

Restrepo, A. (2007). L'instrumentation du déplacement dans un environnement de géométrie dynamique, in I. Bloch \& F. Conne (dir.), Nouvelles perspectives en didactique des mathématiques, La Pensée sauvage.

Rouquès, J.-P., \& Staïner, H. (2009). Des maths ensemble et pour chacun $4^{e}$. Mise en oeuvre du programme de collège et du socle commun. Nantes : CRDP des pays de la Loire.

Ruthven, K. (2009). An investigative lesson with dynamic geometry: a case study of key structuring features of technology integration in classroom practice, in V. Durand-Guerrier, S. Soury-Lavergne \& F. Arzarello (eds.), Proceedings of the Sixth European Conference on Research on Mathematics Education, (pp. 3691378), INRP www.inrp.fr/editions/cerme6

Tapan, S. (2006). Différents types de savoirs mis en œuvre dans la formation initiale d'enseignants de mathématiques à l'intégration de technologies de géométrie dynamique. Thèse de Doctorat de l'Université Joseph Fourier, Grenoble

Trgalova, J., Jahn, A.-P., Soury-Lavergne, S. (2009). Quality process for dynamic geometry resources: the Intergeo project, in V. Durand-Guerrier, S. Soury-Lavergne \& F. Arzarello (eds.), Proceedings of the Sixth European Conference on Research on Mathematics Education (pp. 1161-1170), INRP www.inrp.fr/editions/cerme6

Trouche, L., \& Drijvers, P. (2010). Handheld technology for mathematics education, flashback to the future, ZDM, The International Journal on Mathematics Education, on line http://www.springerlink.com/content/68n07260752h5260/

Trouche, L., \& Guin, D. (2005). Distance training, a key mode to support teachers in the integration of ICT? in M. Bosch (ed.), Proceedings of the Fourth European Conference on Research on Mathematics Education, (pp. 1020-1029), FUNDEMI IQS - Universitat Ramon Llull http://ermeweb.free.fr/CERME4/CERME4_WG9.pdf

Vergnaud, G. (1998). Toward a cognitive theory of practice, in A. Sierpinska, \& J. Kilpatrick (eds.), Mathematics education as a research domain: A search for identity (pp. 227-241). Dordrecht: Kluwer Academic Publishers.

Verillon, P., Rabardel, P. (1995). Cognition and artifacts: A contribution to the study of thought in relation to instrument activity. European Journal of Psychology in Education, 9(3), 77-101.

Vygotski, L. (1978). Mind in society. Cambridge, MA: Harvard University Press.

Wenger, E. (1998). Communities of practice. Learning, meaning, identity. New York: Cambridge University Press. 